\title{
Murine Models of B-Cell Lymphomas: Promising Tools for Designing Cancer Therapies
}

\author{
Sabrina Donnou, ${ }^{1,2,3}$ Claire Galand, ${ }^{1,2,3}$ Valérie Touitou, 1, 2,3,4 \\ Catherine Sautès-Fridman, ${ }^{1,2,3}$ Zsuzsanna Fabry, $^{5}$ and Sylvain Fisson ${ }^{1,2,3,6,7,8}$
}

\author{
${ }^{1}$ Institut National de la Santé et de la Recherche Médicale (INSERM), UMRS 872, Équipe Microenvironnement Immunitaire \\ des Tumeurs, Centre de Recherche des Cordeliers, 75006 Paris, France \\ ${ }^{2}$ Université Pierre et Marie Curie-Paris 6, UMRS 872, 75006 Paris, France \\ ${ }^{3}$ Université Paris Descartes, UMRS 872, 75006 Paris, France \\ ${ }^{4}$ Service d'Ophtalmologie, Hôpital de la Pitié-Salpêtrière, AP-HP, 75013 Paris, France \\ ${ }^{5}$ Department of Pathology, University of Wisconsin, School of Medicine and Public Health, Madison, WI 53706, USA \\ ${ }^{6}$ Généthon, Evry, France \\ ${ }^{7}$ INSERM, UMRS 951, Evry, France \\ ${ }^{8}$ University of Evry Val d'Essonne, UMRS 951, Evry, France
}

Correspondence should be addressed to Sylvain Fisson, sylvain.fisson@univ-evry.fr

Received 28 July 2011; Accepted 21 October 2011

Academic Editor: Kikkeri N. Naresh

Copyright (C) 2012 Sabrina Donnou et al. This is an open access article distributed under the Creative Commons Attribution License, which permits unrestricted use, distribution, and reproduction in any medium, provided the original work is properly cited.

\begin{abstract}
Human B-cell lymphomas, the fourth most common hematologic malignancy, are currently the subject of extensive research. The limited accessibility of biopsies, the heterogeneity among patients, and the subtypes of lymphomas have necessitated the development of animal models to decipher immune escape mechanisms and design new therapies. Here, we summarize the cell lines and murine models used to study lymphomagenesis, the lymphoma microenvironment, and the efficacy of new therapies. These data allow us to understand the role of the immune system in the fight against tumors. Exploring the advantages and limitations of immunocompetent versus immunodeficient models improves our understanding of the molecular and cellular mechanisms of tumor genesis and development as well as the fundamental processes governing the interaction of tumors and their host tissues. We posit that these basic preclinical investigations will open up new and promising approaches to designing better therapies.
\end{abstract}

\section{Introduction}

Lymphomas are highly heterogeneous diseases, varying by both the type of malignant cell and the tumor location. They most frequently originate from $\mathrm{B}$ cells, and the two main groups of B-cell lymphomas, B-cell non-Hodgkin lymphomas (NHL) and Hodgkin lymphomas, account, respectively, for about $80 \%$ and $15 \%$ of all lymphomas. Of the NHL, half are diffuse large B-cell lymphomas, followed in prevalence by follicular lymphomas, marginal zone lymphomas, Burkitt's lymphomas, and mediastinal lymphomas. This heterogeneity makes it difficult to collect human samples in sufficient quantities for statistical analyses. Moreover, these samples are not easy to classify in the absence of clear discriminative parameters. In addition, some tumors, such as primary central nervous system (CNS) lymphomas, are located deep within delicate tissues, which complicates the collection of biopsy samples and complete tumor analysis [1]. Studying these tumors is thus quite challenging. Animal models are very useful, because they let us work on very homogeneous materials. They are also essential for preclinical studies and allow us to perform kinetic analyses together with detailed investigation of the tumors' characteristics and microenvironments. Here, we will review the spontaneous and induced B-cell lymphoma models that can occur in transgenic mice, or by various types of transfer of tumor cells into 
wild-type mice (Figure 1). We will summarize the known categories of B-cell lymphoma mouse models and discuss their experimental and translational values. Finally, we will examine how the tumors regulate their microenvironment in different tissues and how this knowledge could be translated into practical applications for tumor therapies.

\section{Models for Studying Lymphomagenesis}

One of the key questions about tumor development concerns the origin and the mechanisms responsible for malignant phenotypes. Various spontaneous tumor models have been developed to study how B-cell lymphomas arise and mature in different tumor environments. Observations and experiments with human tissue samples have provided some indications about the possible genetic events that might be responsible for uncontrolled B-cell proliferation. Recent advances in genetic engineering have made it possible to develop transgenic mouse models recapitulating major known modifications of the genome and to infect mice with viruses that can induce B-cell lymphomas.

The myc oncogene is the gene most frequently studied: its translocation behind an enhancer or promoter region specific for B lymphocytes can give rise to B-cell lymphomas (Table 1). The involvement of such a translocation in lymphomagenesis is studied in the most used mouse model, E $\mu$ Myc. In this transgenic experimental tumor model, when the myc gene is inserted into the IgH locus, B-cell lymphomas develop at a $100 \%$ incidence rate. Nonetheless, disease onset is, as in humans, highly variable (from day 32 to day 600), as is the phenotype of the tumors in different mice. More precisely, Mori and colleagues [14] have described two principal tumor phenotypes: the first type arises during an early time window and is composed mainly of immature B cells, thus resembling Burkitt's lymphoma. The second type develops very late (after day 400) and is composed of mature B cells; it is similar to diffuse large B-cell lymphomas [14]. Interestingly, if the myc gene is placed under the enhancer region of the Ig light chain genes, it results in a disease very similar to Burkitt's lymphoma in humans [7] (Table 1). Sheppard and colleagues [4] generated another transgenic mouse with the translocation of the $\mathrm{N}$-myc gene under the IgH enhancer and with only a subtle modification of the endogenous myc expression level. This resulted in an indolent disease and only $25 \%$ incidence after 9 to 12 months. After infection with the murine Moloney leukemia virus, however, both the incidence and speed of tumor development were far greater. Following this idea, others developed a model that uses the Brd2 gene and can induce B-cell lymphoma in some mice after translocation but is not sufficient to obtain a high incidence. Modification of these mice by infection with a retrovirus expressing the ras oncogene also aggravated and accelerated lymphomagenesis [10] (Table 1). These results point out that translocation of the oncogene by itself is not sufficient to create a malignant phenotype. The added value of these transgenic models is that tumors develop on a syngeneic background that makes it possible to analyze the tumor microenvironment and its influence on tumor growth. For example,

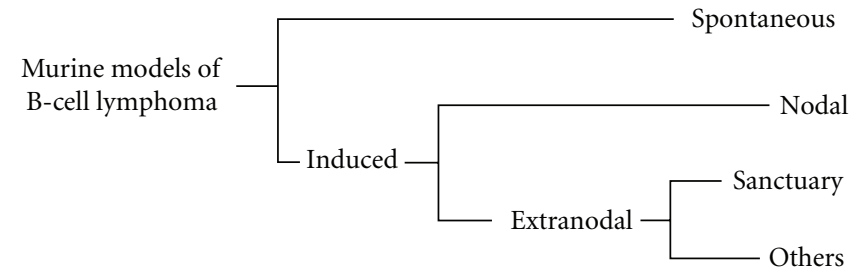

FIGURE 1: Schematic representation of the major subtypes of Bcell lymphoma murine models. Murine models can be either spontaneous and develop in genetically engineered mice or can be induced by implantation of a tumor cell line. In this case, it is possible to inject cells in lymph nodes (nodal location) or outside of them (extranodal location). Immune sanctuaries such as the brain or the eyes provide information about that particular situation, but many other sites can be envisaged.

by studying the influence of $\mathrm{Bcl} 2$ overexpression in the hematologic compartment in generating a follicular B-cell lymphoma, Egle and collaborators [8] were able to determine that $\mathrm{CD} 4^{+} \mathrm{T}$ cells were crucial in the proliferation of germinal center B cells and therefore in lymphomagenesis.

To understand the mechanisms linked to lymphomagenesis in more detail, researchers have introduced more strategies to transfer variously modified tumor cells into immunodeficient or immunocompromised hosts (models listed in Tables 2 and 3 ). These approaches introduce the potential bias of tumor injection to specific tissue sites and are unable to follow the progressive induction and development of tumors from a few malignant cells. Despite these weaknesses, tumor injection models are very useful because they let us study the impact of different mutations on tumor aggressiveness (models listed in Table 2). For example, the potential role of pax 5 in lymphomagenesis was studied with cell lines deficient for this gene [17]. Using the same idea, Yu and collaborators [18] developed a strategy to determine the influence of different genes in enhancing the tumor-inducing potential of the myc gene translocation (Table 3 ). By mixing bone marrow from p53 null mice with a packaging cell line producing the myc-encoding retrovirus, they demonstrated that p53 inactivation together with myc overexpression was sufficient to induce B-cell lymphomas. These models could easily and rapidly be adapted to help define the effect of other genes and gene interactions on lymphomagenesis without the need to develop transgenic mice.

The diversity of the animal models listed in Tables 1-3 makes it very challenging to study the influence of different characteristics on the development of specific types of tumors in experimental animals and to draw significant conclusions about human B-cell lymphoma development. Some models are heterogeneous [14] or can only be classified depending on the differentiation stage of the tumor cells used [47], while some transgenic mice are clearly associated with specific B-cell lymphoma phenotypes. Some models are nonetheless very useful for studying human disease. For example, because NFS.V mice develop tumors that are very similar to marginal zone lymphomas [5], they provided a basis for defining its stages of progression (Table 1). Another highly relevant tumor model is the blastoid variant of mantle 
TABLE 1: Spontaneous models of B-cell lymphoma. B-NHL: non-Hodgkin B-cell lymphoma; CLL: chronic lymphocytic leukemia; DLBCL: diffuse large B-cell lymphoma; DTG: double transgenic mice; n.d.: not determined.

\begin{tabular}{|c|c|c|c|}
\hline Name & Lymphoma subtype/orgin & Strain (haplotype) & $\begin{array}{l}\text { Major } \\
\text { reference }\end{array}$ \\
\hline $\mathrm{B} 10 \mathrm{H}-2^{\mathrm{a}} \mathrm{H}-4^{\mathrm{b}} \mathrm{p} / \mathrm{Wts}$ & CLL & $\mathrm{C} 57 \mathrm{Bl} / 10\left(\mathrm{H}-2^{\mathrm{b}}\right)$ & {$[2]$} \\
\hline $\mathrm{SL} / \mathrm{KH}$ & Pre-B lymphoma & $\mathrm{SL} / \mathrm{KH}\left(\mathrm{H}-2^{11}\right)$ & {$[3]$} \\
\hline $\mathrm{E} \mu-\mathrm{N}-\mathrm{myc}$ & Indolent B-NHL & $\mathrm{C} 57 \mathrm{Bl} / 6 \times \mathrm{DBA} / 2\left(\mathrm{H}-2^{\mathrm{b} / \mathrm{d}}\right)$ & {$[4]$} \\
\hline NFS.V+ & Marginal zone lymphoma & NFS.V $+\left(H-2^{\text {sq4}}\right)$ & {$[5]$} \\
\hline NMRI/RFB-MuLV & n.d. & NMRI (H-2q) & {$[6]$} \\
\hline B6-1-MYC & Burkitt-like lymphoma & $\mathrm{C} 57 \mathrm{Bl} / 6\left(\mathrm{H}-2^{\mathrm{b}}\right)$ & [7] \\
\hline VavP-Bcl2 & Follicular lymphoma & $\mathrm{C} 57 \mathrm{Bl} / 6\left(\mathrm{H}-2^{\mathrm{b}}\right)$ & {$[8]$} \\
\hline Lig4/p53 KO & Pro/Pre-B lymphoma & $\mathrm{C} 57 \mathrm{Bl} / 6 \times \operatorname{sv} 129$ & {$[9]$} \\
\hline $\mathrm{E} \mu-\mathrm{BRD} 2$ & DLBCL & $\operatorname{FVB}\left(\mathrm{H}-2^{\mathrm{q}}\right)$ & {$[10]$} \\
\hline Bcl6 Knock in & Germinal center, DLBCL & $\mathrm{C} 57 \mathrm{Bl} / 6 \times \mathrm{sv} 129$ & {$[11]$} \\
\hline Bcl6/Myc transgenic & Post germinal center, DLBCL & $\mathrm{C} 57 \mathrm{Bl} / 6 \times \operatorname{sv} 129$ & {$[11]$} \\
\hline IL-14aTGxc-Myc TG (DTG) & Blastoid variant of mantle-cell lymphoma & $\mathrm{C} 57 \mathrm{Bl} / 6\left(\mathrm{H}-2^{\mathrm{b}}\right)$ & {$[12]$} \\
\hline $\mathrm{Myc} / \mathrm{BCR}^{\mathrm{HEL}} / \mathrm{HEL}$ & Burkitt-like lymphoma & $\mathrm{C} 57 \mathrm{Bl} / 6\left(\mathrm{H}-2^{\mathrm{b}}\right)$ & {$[13]$} \\
\hline $\mathrm{E} \mu$-myc & From follicular to DLBCL (time dependant) & $\mathrm{C} 57 \mathrm{Bl} / 6 \times \operatorname{sv} 129$ & {$[14]$} \\
\hline RzCD19Cre & NHL, hepatitis C induced & $129 / \mathrm{Sv}\left(\mathrm{H}-2^{\mathrm{bc}}\right) ; \mathrm{BALB} / \mathrm{c}\left(\mathrm{H}-2^{\mathrm{d}}\right) ; \mathrm{C} 57 \mathrm{Bl} / 6\left(\mathrm{H}-2^{\mathrm{b}}\right)$ & {$[15]$} \\
\hline UVB induced & Mature B-cell lymphoma & $\mathrm{C} 57 \mathrm{Bl} / 6 \mathrm{p} 53^{+/-}\left(\mathrm{H}-2^{\mathrm{b}}\right)$ & {$[16]$} \\
\hline
\end{tabular}

cell lymphoma, developed by Ford and colleagues [12] by generation of double-transgenic mice for the IL-14a and myc genes (Table 3). A more recent model with the full genome of the hepatitis C virus introduced into CD19-expressing cells spontaneously develops human diffuse large B-cell lymphoma [15]. A nontransgenic strategy also led to the development of a model of mucosa-associated lymphoid tissue lymphoma, shown to recapitulate most human disease characteristics [48].

The major advantage of the after mentioned models is that they develop through multiple spontaneous genetic events that will help us to discover novel mechanisms of tumorigenesis. At the same time, they are also associated with some experimental limitations. First, time to onset of disease varies enormously within and between models (from day 32 to day 600 for some models), precluding the assessment of new therapies in these conditions. Moreover, as described previously, tumor incidence is high but disparate, up to $100 \%$ in some cases, but not higher than $25 \%$ in others. Furthermore, in a given model system, these tumors can vary greatly in tumor location and phenotype, which makes it difficult to compare different animals in the same experiment. While it is clear that spontaneous B-cell lymphoma models provide unique insight into tumor development, we must nonetheless bear in mind that the in vivo tumor generation process is quite complex. These models, together with the adoptive tumor transfer models, will be critical to our understanding of lymphomagenesis.

\section{Models to Study the Lymphoma Microenvironment}

The tumor microenvironment is an essential and complicating aspect of a tumor that must be better understood if more targeted treatments are to be developed [49]. Studying all the features of a malignancy requires working on syngeneic models. Moreover, reproducible models with wellcharacterized tumor development are important for the analysis of immune response, which remains impossible with spontaneous models. Two main questions must be addressed in developing such models: the tumor cells to be injected and the site of tumor injection, that is, nodal or extranodal, in the peripheral or central nervous system. The tumor cells are of human origin and therefore implanted into immunodeficient mice, or, more often, they are syngeneic to their host, so the tumor-induced immunity can be studied (Table 2). Lymphomas can invade many different organs in humans, especially secondary lymphoid organs and the central nervous system. Tumor cells may be injected into these organs in the mouse or directly into the blood; the latter allows spontaneous tumor colonization to different locations. The advantages of targeting a specific tissue include the possibility of comparing tumor growth between different microenvironments and determining the relative roles in tumor development of the tissue characteristics and the intrinsic tumor cell characteristics [50].

To study the microenvironment of B-cell lymphomas in different tissues, we implanted a tumor cell line derived from the well-known A20 tumor into different tissue locations, including the spleen, brain, and eyes, in syngeneic mice [ 45 , 50]. As Figure 2 illustrates, $T$ cells infiltrated the tumor at each location, even immune-privileged tissues, and represented up to $15 \%$ of all live cells in these sites. Moreover, antigen-presenting cells also infiltrated into the A20.IIA-GFP tumor, particularly in the brain where $\mathrm{CD} 11 \mathrm{c}^{+}$dendritic cells and $\mathrm{CD} 11 \mathrm{~b}^{+} \mathrm{CD} 11 \mathrm{c}^{-}$macrophages accounted for a higher proportion of cells than in the tumor-bearing eye or spleen. Innate immune cells were also found in the tumor microenvironment, especially in the brain and spleen (Figure 2). The absence of spontaneous tumor rejection in these experiments 
TABLE 2: Most common B lymphoma cell lines. B-NHL: non-Hodgkin B-cell lymphoma; DLBCL: diffuse large B-cell lymphoma; N/A: not attributable.

\begin{tabular}{|c|c|c|c|}
\hline Name & Orgin & Strain (haplotype) & Reference \\
\hline L1210 & $\begin{array}{c}\text { Ascitic fluid of } 8 \text { months mouse, lymphocytic leukemia } \\
\text { cells }\end{array}$ & $\mathrm{DBA} / 2\left(\mathrm{H}-2^{\mathrm{d}}\right)$ & {$[19]$} \\
\hline Raji & Burkitt lymphoma from an 11-year-old child (maxilla) & N/A & {$[20]$} \\
\hline Jijoye & $\begin{array}{l}\text { Lymphoblastic cell line derived from a 7-year old boy with } \\
\text { Burkitt lymphoma } \mathrm{EBV}^{+}\end{array}$ & N/A & {$[21]$} \\
\hline Daudi & $\begin{array}{c}\text { 16-year-old black male with Burkitt lymphoma, orbital } \\
\text { tumor }\end{array}$ & N/A & {$[22]$} \\
\hline Ramos & Burkitt lymphoma & N/A & {$[23]$} \\
\hline BJAB & Burkitt lymphoma & N/A & {$[24]$} \\
\hline SU-DHL-4 & $\begin{array}{l}\text { DLBCL patient (peritoneal effusion of woman with } \\
\text { B-NHL) }\end{array}$ & N/A & {$[25]$} \\
\hline $38 \mathrm{C} 13$ & Carcinogen induced & $\mathrm{C} 3 \mathrm{H} / \mathrm{HeN}\left(\mathrm{H}-2^{\mathrm{k}}\right)$ & {$[26]$} \\
\hline BCL1 & Spontaneous & $\mathrm{BALB} / \mathrm{c}\left(\mathrm{H}-2^{\mathrm{d}}\right)$ & {$[27]$} \\
\hline A20 & Spontaneous reticulum cell sarcoma of an old mouse & $\mathrm{BALB} / \mathrm{c}\left(\mathrm{H}-2^{\mathrm{d}}\right)$ & {$[28]$} \\
\hline CA46 & Ascite fluid of a patient with Burkitt lymphoma & N/A & [29] \\
\hline MC116 & Undifferenciated B cell lymphoma & N/A & [29] \\
\hline $4 \mathrm{TOO}$ & Plasmacytoma originating from MPC-11 cells & $\mathrm{BALB} / \mathrm{c}\left(\mathrm{H}-2^{\mathrm{d}}\right)$ & {$[30]$} \\
\hline B6 spontaneous model & Spontaneous & $\mathrm{C} 57 \mathrm{Bl} / 6\left(\mathrm{H}-2^{\mathrm{b}}\right)$ & {$[31]$} \\
\hline L3055 & Burkitt's lymphoma of germinal center origin & N/A & {$[32]$} \\
\hline SC-1 & Burkitt lymphoma & N/A & {$[33]$} \\
\hline $\mathrm{CH} 44$ & $\begin{array}{l}\text { Follicular center cell lymphoma derived from } \\
\text { B10.H-2a/H-4bp/Wts, large cell type }\end{array}$ & B10.H- $2^{\mathrm{a}} \mathrm{H}-4^{\mathrm{b}} \mathrm{p} / \mathrm{Wts}\left(\mathrm{H}-2^{\mathrm{a}}-4^{\mathrm{b}}\right)$ & {$[34]$} \\
\hline DoHH-2 & $\begin{array}{c}\text { Pleural fluid of } 60 \text {-year old man with centroblastic } \\
\text { non-Hodgkin lymphoma }\end{array}$ & N/A & {$[35]$} \\
\hline S11 & From Gammaherpesvirus-68-infected mice & $\mathrm{BALB} / \mathrm{c}\left(\mathrm{H}-2^{\mathrm{d}}\right)$ & {$[36]$} \\
\hline LY-ar / LY-as & Derived from the spontaneous LY-TH tumor & $\mathrm{C} 3 \mathrm{Hf} / \mathrm{kam}$ & {$[37]$} \\
\hline Granta 519 & Peripheral blood at relapse of high grade B-NHL & N/A & {$[38]$} \\
\hline Pi-BCL1 & Prolymphocytic, foetal liver derived & $\mathrm{BALB} / \mathrm{c}\left(\mathrm{H}-2^{\mathrm{d}}\right)$ & {$[39]$} \\
\hline 38C13 Her2/neu & Carcinogen induced & $\mathrm{C} 3 \mathrm{H} / \mathrm{HeN}\left(\mathrm{H}-2^{\mathrm{k}}\right)$ & {$[40]$} \\
\hline Myc5-M5 & $\begin{array}{l}\text { Derived from a tumor induced in p53 null mice infected } \\
\text { with myc encoding retrovirus }\end{array}$ & $\mathrm{C} 57 \mathrm{Bl} / 6\left(\mathrm{H}-2^{\mathrm{b}}\right)$ & {$[18]$} \\
\hline Mouse lymphosarcoma cell line & Nitrosomethylurea induced & $\mathrm{CBA}\left(\mathrm{H}-2^{\mathrm{k}}\right)$ & {$[41]$} \\
\hline FL5.12 transfected by $\mathrm{Bcl} 2$ & IL-3-dependant BALB/c pro-B cell line & $\mathrm{BALB} / \mathrm{c}\left(\mathrm{H}-2^{\mathrm{d}}\right)$ & {$[42]$} \\
\hline $38 \mathrm{C} 13 \mathrm{CD} 20^{+}$ & Carcinogen induced & $\mathrm{C} 3 \mathrm{H} / \mathrm{HeN}\left(\mathrm{H}-2^{\mathrm{k}}\right)$ & {$[43]$} \\
\hline Z138 & Mantle cell lymphoma with blastoid transformation & N/A & {$[44]$} \\
\hline A20.IIA-GFP / IIA1.6-GFP & Reticulum cell sarcoma & $\mathrm{BALB} / \mathrm{c}\left(\mathrm{H}-2^{\mathrm{d}}\right)$ & {$[45]$} \\
\hline HKBML & Brain lymphoma & N/A & {$[46]$} \\
\hline
\end{tabular}

indicates an immunosuppressive environment. Strikingly, nonetheless, even immune-privileged sites such as the eye or the brain were able to induce an immune response, with cellular and molecular environments similar to those of peripheral tissue sites. These findings suggest that the primary regulator of the tumor microenvironment is the tumor itself rather than the local tissue structure.

Even so, we note some features specific to CNS tumors, in particular the delay in the infiltration of T cells, especially $\mathrm{CD}^{+} \mathrm{T}$ cells, into the eye and the brain. Moreover, we observed among these infiltrated $\mathrm{T}$ cells a large proportion of $\mathrm{CD} 4{ }^{+} \mathrm{CD} 25^{+}$Foxp $^{+}$regulatory $\mathrm{T}$ cells, accounting for up to $40 \%$ of all $\mathrm{CD}^{+} \mathrm{T}$ lymphocytes, compared with no more than $20 \%$ in the spleen [50]. In related findings, Elpek and colleagues [74], using the parental A20 cell line implanted subcutaneously, highlighted the importance of regulatory $\mathrm{T}$ cells in the early phase of tumor growth. Curti's group [60] used the same cell line in an intrasplenic tumor model to study the accumulation of regulatory $\mathrm{T}$ cells in the spleen and showed that the IDO enzyme is critical for the local conversion of conventional $\mathrm{T}$ cells into regulatory ones. Serafini's team [75] showed that a robust expansion of specific regulatory $\mathrm{T}$ cells follows intravenous injection of A20 cells and demonstrated that a population of myeloid-derived suppressive cells is responsible for this expansion. Others have also suggested that myeloid-derived cells can contribute 
TABLE 3: Induced models of B-cell lymphoma. (m): murine origin; (h): human origin; (i): syngeneic models; (ii): syngeneic models with murine tumor cells engineered to express human antigens; (iii): xenogenic models; (iv): humanized models; CLL: chronic lymphocytic leukemia; DLBCL: diffuse large B-cell lymphoma; MALT: mucosa associated lymphatic tissue; n.d.: not determined; PCL: primary cerebral lymphoma; PCNSL: primary central nervous system lymphoma; PIOL: primary intraocular lymphoma; SCID: severe combined immune deficiency.

\begin{tabular}{|c|c|c|c|c|c|c|}
\hline \multirow{2}{*}{ Injection site } & \multirow{2}{*}{ Name } & \multirow{2}{*}{ Lymphoma model } & \multicolumn{3}{|c|}{ Recipient mice } & \multirow{2}{*}{$\begin{array}{l}\text { Major } \\
\text { reference }\end{array}$} \\
\hline & & & Strain (haplotype) & MHC compatibility & Immune status & \\
\hline \multirow[t]{11}{*}{ Intravenous } & $\begin{array}{l}\text { B6 spontaneous } \\
\text { model }(\mathrm{m})\end{array}$ & $\begin{array}{l}\text { High-grade B } \\
\text { lymphoma }\end{array}$ & $\mathrm{C} 57 \mathrm{Bl} / 6\left(\mathrm{H}-2^{\mathrm{b}}\right)$ & Syngeneic (i) & Immunocompetent & {$[51]$} \\
\hline & Pi-BCL1 (m) & DLBCL & $\mathrm{BALB} / \mathrm{c}\left(\mathrm{H}-2^{\mathrm{d}}\right)$ & Syngeneic (i) & Immunocompetent & {$[52]$} \\
\hline & $38 \mathrm{C} 13(\mathrm{~m})$ & $\begin{array}{l}\text { Non-Hodgkin } \\
\text { lymphoma }\end{array}$ & $\mathrm{C} 3 \mathrm{H} / \mathrm{HeN}\left(\mathrm{H}-2^{\mathrm{k}}\right)$ & Syngeneic (i) & Immunocompetent & {$[53]$} \\
\hline & $\begin{array}{l}\text { FL5.12 transfected by } \\
\text { Bcl } 2(\mathrm{~m})\end{array}$ & $\begin{array}{l}\text { Non-Hodgkin } \\
\text { lymphoma }\end{array}$ & $\mathrm{BALB} / \mathrm{c}\left(\mathrm{H}-2^{\mathrm{d}}\right)$ & Syngeneic (i) & Immunocompetent & {$[42]$} \\
\hline & $\mathrm{A} 20(\mathrm{~m})$ & DLBCL & $\mathrm{BALB} / \mathrm{c}\left(\mathrm{H}-2^{\mathrm{d}}\right)$ & Syngeneic (i) & Immunocompetent & {$[54]$} \\
\hline & $4 \mathrm{TOO}(\mathrm{m})$ & n.d. & $\mathrm{BALB} / \mathrm{c}\left(\mathrm{H}-2^{\mathrm{d}}\right)$ & Syngeneic (i) & Immunocompetent & {$[55]$} \\
\hline & $\mathrm{BCL} 1(\mathrm{~m})$ & CLL & $\mathrm{BALB} / \mathrm{c}\left(\mathrm{H}-2^{\mathrm{d}}\right)$ & Syngeneic (i) & Immunocompetent & {$[56]$} \\
\hline & 38C13 Her2/neu (m) & $\begin{array}{l}\text { Non-Hodgkin } \\
\text { lymphoma }\end{array}$ & $\mathrm{C} 3 \mathrm{H} / \mathrm{HeN}\left(\mathrm{H}-2^{\mathrm{k}}\right)$ & Syngeneic (ii) & Immunocompetent & {$[40]$} \\
\hline & Z138 (h) & $\begin{array}{l}\text { Human mantle cell } \\
\text { lymphoma }\end{array}$ & SCID mice $\left(\mathrm{H}-2^{\mathrm{d}}\right)$ & Xenogenic (iii) & Immunodeficient & {$[57]$} \\
\hline & BJAB (h) & Burkitt lymphoma & SCID mice $\left(\mathrm{H}-2^{\mathrm{d}}\right)$ & Xenogenic (iii) & Immunodeficient & {$[58]$} \\
\hline & SU-DHL-4 (h) & DLBCL & SCID mice $\left(\mathrm{H}-2^{\mathrm{d}}\right)$ & Xenogenic (iii) & Immunodeficient & {$[59]$} \\
\hline \multirow[t]{2}{*}{ Intrasplenic } & $\mathrm{A} 20(\mathrm{~m})$ & DLBCL & $\mathrm{BALB} / \mathrm{c}\left(\mathrm{H}-2^{\mathrm{d}}\right)$ & Syngeneic (i) & Immunocompetent & {$[60]$} \\
\hline & A20.IIA-GFP (m) & DLBCL & $\mathrm{BALB} / \mathrm{c}\left(\mathrm{H}-2^{\mathrm{d}}\right)$ & Syngeneic (i) & Immunocompetent & {$[50]$} \\
\hline \multirow[t]{4}{*}{ Intraperitoneal } & $\mathrm{CH} 44(\mathrm{~m})$ & $\begin{array}{l}\text { Non-Hodgkin } \\
\text { lymphoma }\end{array}$ & B10.H-2 $2^{\mathrm{a}} \mathrm{H}-4^{\mathrm{b}} \mathrm{p} / \mathrm{Wts}$ & Syngeneic (i) & Immunocompetent & {$[34]$} \\
\hline & $\mathrm{BCL} 1(\mathrm{~m})$ & DLBCL & $\mathrm{BALB} / \mathrm{c}\left(\mathrm{H}-2^{\mathrm{d}}\right)$ & Syngeneic (i) & Immunocompetent & {$[53]$} \\
\hline & $38 \mathrm{C} 13(\mathrm{~m})$ & $\begin{array}{l}\text { Non-Hodgkin } \\
\text { lymphoma }\end{array}$ & $\mathrm{C} 3 \mathrm{H} / \mathrm{HeN}\left(\mathrm{H}-2^{\mathrm{k}}\right)$ & Syngeneic (i) & Immunocompetent & {$[53]$} \\
\hline & $\begin{array}{l}\text { Tonsillar lymphocytes } \\
\text { and EBV infection }(\mathrm{h})\end{array}$ & $\begin{array}{l}\text { Viro-induced } \\
\text { lymphoma }\end{array}$ & $\begin{array}{c}\text { BNXhum } \\
\text { (humanized) }\end{array}$ & Allogenic (iv) & Immunocompetent & {$[61]$} \\
\hline \multirow[t]{15}{*}{ Subcutaneous } & LY-ar or LY-as (m) & n.d. & C3Hf/kam $\left(\mathrm{H}-2^{\mathrm{k}}\right)$ & Syngeneic (i) & Immunocompetent & {$[37]$} \\
\hline & $\mathrm{S} 11(\mathrm{~m})$ & Burkitt lymphoma & $\mathrm{BALB} / \mathrm{c}$ nude $\left(\mathrm{H}-2^{\mathrm{d}}\right)$ & Syngeneic (i) & T-cell deficiency & {$[62]$} \\
\hline & LMycSN-p53null (m) & $\begin{array}{l}\text { Non-Hodgkin } \\
\text { lymphoma }\end{array}$ & $\mathrm{C} 57 \mathrm{Bl} / 6\left(\mathrm{H}-2^{\mathrm{b}}\right)$ & Syngeneic (i) & Immunocompetent & {$[18]$} \\
\hline & $\mathrm{A} 20(\mathrm{~m})$ & DLBCL & $\mathrm{BALB} / \mathrm{c}\left(\mathrm{H}-2^{\mathrm{d}}\right)$ & Syngeneic (i) & Immunocompetent & {$[63]$} \\
\hline & 38C13 Her2/neu (m) & $\begin{array}{l}\text { Non-Hodgkin } \\
\text { lymphoma }\end{array}$ & $\mathrm{C} 3 \mathrm{H} / \mathrm{HeN}\left(\mathrm{H}-2^{\mathrm{k}}\right)$ & Syngeneic (ii) & Immunocompetent & {$[40]$} \\
\hline & Myc5-M5 (m) & n.d. & SCID mice $\left(\mathrm{H}-2^{\mathrm{d}}\right)$ & Allogenic & Immunodeficient & {$[17]$} \\
\hline & $\begin{array}{l}\text { Splenic Hodgkin } \\
\text { lymphoma cells (h) }\end{array}$ & Hodgkin disease & Nude mice $\left(\mathrm{H}-2^{\mathrm{b}}\right)$ & Xenogenic (iii) & T-cell deficiency & {$[64]$} \\
\hline & $\begin{array}{c}\text { Human hodgkin cell } \\
\text { line }(\mathrm{h})\end{array}$ & Hodgkin disease & SCID mice $\left(\mathrm{H}-2^{\mathrm{d}}\right)$ & Xenogenic (iii) & Immunodeficient & {$[47]$} \\
\hline & Ramos (h) & Burkitt lymphoma & SCID mice $\left(\mathrm{H}-2^{\mathrm{d}}\right)$ & Xenogenic (iii) & Immunodeficient & {$[58]$} \\
\hline & BJAB (h) & Burkitt lymphoma & SCID mice $\left(\mathrm{H}-2^{\mathrm{d}}\right)$ & Xenogenic (iii) & Immunodeficient & {$[58]$} \\
\hline & SC-1 (h) & Follicular lymphoma & SCID mice $\left(\mathrm{H}-2^{\mathrm{d}}\right)$ & Xenogenic (iii) & Immunodeficient & {$[58]$} \\
\hline & DoHH-2 (h) & Follicular lymphoma & SCID mice $\left(\mathrm{H}-2^{\mathrm{d}}\right)$ & Xenogenic (iii) & Immunodeficient & {$[58]$} \\
\hline & SuDHL-4 (h) & DLBCL & $\begin{array}{l}\text { C.B-17 SCID mice } \\
\qquad\left(\mathrm{H}-2^{\mathrm{d}}\right)\end{array}$ & Xenogenic (iii) & Immunodeficient & {$[65]$} \\
\hline & Granta $519(\mathrm{~h})$ & $\begin{array}{l}\text { Mantle cell } \\
\text { lymphoma }\end{array}$ & $\begin{array}{l}\text { C.B-17 SCID mice } \\
\left(\mathrm{H}-2^{\mathrm{d}}\right)\end{array}$ & Xenogenic (iii) & Immunodeficient & {$[65]$} \\
\hline & HKBML (h) & Brain DLBCL & $\begin{array}{l}\text { C.B-17 SCID mice } \\
\left(\mathrm{H}-2^{\mathrm{d}}\right)\end{array}$ & Xenogenic (iii) & Immunodeficient & {$[46]$} \\
\hline
\end{tabular}


TABle 3: Continued.

\begin{tabular}{|c|c|c|c|c|c|c|}
\hline \multirow{2}{*}{ Injection site } & \multirow{2}{*}{ Name } & \multirow{2}{*}{ Lymphoma model } & \multicolumn{3}{|c|}{ Recipient mice } & \multirow{2}{*}{$\begin{array}{l}\text { Major } \\
\text { reference }\end{array}$} \\
\hline & & & Strain (haplotype) & MHC compatibility & Immune status & \\
\hline & Daudi (h) & Burkitt lymphoma & $\begin{array}{c}\text { SCID/beige mice } \\
\left(\mathrm{H}-2^{\mathrm{d}}\right)\end{array}$ & Xenogenic (iv) & Partially rebuilt & {$[66]$} \\
\hline & Jijoye (h) & Burkitt lymphoma & $\begin{array}{l}\text { SCID/beige mice } \\
\left(\mathrm{H}-2^{\mathrm{d}}\right)\end{array}$ & Xenogenic (iv) & Partially rebuilt & {$[66]$} \\
\hline \multirow[t]{2}{*}{ Intramuscular } & $\begin{array}{l}\text { MSV-MuLV-M } \\
\text { induced }\end{array}$ & $\begin{array}{c}\text { Waldenstrom's } \\
\text { macroglobulinemia }\end{array}$ & $\mathrm{C} 57 \mathrm{Bl} / 6\left(\mathrm{H}-2^{\mathrm{b}}\right)$ & Syngeneic & Immunocompetent & {$[67]$} \\
\hline & $\begin{array}{c}\text { Mouse } \\
\text { lymphosarcoma cell } \\
\text { line }(\mathrm{m})\end{array}$ & $\begin{array}{l}\text { Non-Hodgkin } \\
\text { lymphosarcoma }\end{array}$ & $\mathrm{CBA}\left(\mathrm{H}-2^{\mathrm{k}}\right)$ & Syngeneic (i) & Immunocompetent & {$[41]$} \\
\hline Stomach & Helicobacter felis & MALT lymphoma & BALB/c $\left(\mathrm{H}-2^{\mathrm{d}}\right)$ & Syngeneic (i) & Immunocompetent & {$[48]$} \\
\hline \multirow[t]{5}{*}{ Intracerebral } & A20.IIA-GFP (m) & PCL (PCNSL) & $\mathrm{BALB} / \mathrm{c}\left(\mathrm{H}-2^{\mathrm{d}}\right)$ & Syngeneic (i) & Immunocompetent & {$[50]$} \\
\hline & $38 \mathrm{C} 13 \mathrm{CD} 20^{+}(\mathrm{m})$ & PCL (PCNSL) & $\mathrm{C} 3 \mathrm{H} / \mathrm{HeN}\left(\mathrm{H}-2^{\mathrm{k}}\right)$ & Syngeneic (ii) & Immunocompetent & {$[68]$} \\
\hline & Raji (h) & PCL (PCNSL) & Nude mice $\left(\mathrm{H}-2^{\mathrm{b}}\right)$ & Xenogenic (iii) & T-cell deficiency & [69] \\
\hline & Patient's cells (h) & PCL (PCNSL) & Nude mice $\left(\mathrm{H}-2^{\mathrm{b}}\right)$ & Xenogenic (iii) & T-cell deficiency & {$[70]$} \\
\hline & MC116 (h) & PCL (PCNSL) & Nude rats $\left(\mathrm{RT} 1^{\mathrm{u}}\right)$ & Xenogenic (iii) & Immunodeficient & {$[71]$} \\
\hline $\begin{array}{l}\text { Cisterna } \\
\text { magna }\end{array}$ & $\mathrm{L} 1210(\mathrm{~m})$ & $\begin{array}{c}\text { Leptomeningeal } \\
\text { metastases }\end{array}$ & $\mathrm{DBA} / 2\left(\mathrm{H}-2^{\mathrm{d}}\right)$ & Syngeneic (i) & Immunocompetent & {$[72]$} \\
\hline \multirow[t]{3}{*}{ Intraocular } & A20.IIA-GFP (m) & PIOL & $\mathrm{BALB} / \mathrm{c}\left(\mathrm{H}-2^{\mathrm{d}}\right)$ & Syngeneic (i) & Immunocompetent & {$[45]$} \\
\hline & $38 \mathrm{C} 13 \mathrm{CD} 20^{+}(\mathrm{m})$ & PIOL & $\mathrm{C} 3 \mathrm{H} / \mathrm{HeN}\left(\mathrm{H}-2^{\mathrm{k}}\right)$ & Syngeneic (ii) & Immunocompetent & {$[68]$} \\
\hline & CA46 (h) & PIOL & SCID mice $\left(\mathrm{H}-2^{\mathrm{d}}\right)$ & Xenogenic (iii) & Immunodeficient & {$[73]$} \\
\hline
\end{tabular}

to the tumor immune response, as when M2 macrophages infiltrate the B-cell lymphoma growing in the brain after implantation of human Raji cells into nude mice [76].

All these results show that B-cell lymphomas induce immunosuppressive cells, although how these cells contribute to tumor growth remains unknown. It is assumed that suppressive myeloid cells can influence the molecular milieu of the tumor. We and others have shown the production of various anti-inflammatory mediators, depending on the experimental setting, including IL-10 [74], IL-4 [76], and soluble receptor for IL-2 [15]. Additionally, as Figure 2 shows, we found that $\mathrm{T}$ cells from tumor-bearing mice do not produce the proinflammatory cytokines IFN $\gamma$ or GM-CSF without stimulation, except in the spleen where resident $\mathrm{T}$ cells might be responsible for this secretion. After polyclonal stimulation we observed an unbalanced Th1/Th17 profile, with high levels of IFN $\gamma$, GM-CSF, and IL-17 and low levels of IL-2, IL-4, and IL-10 [45, 50].

In summary, it is clear that tumor cells closely regulate the microenvironment of B-cell lymphomas. It is advantageous for the tumor to generate a suppressive environment for optimal tumor growth. Understanding the balance between pro- and anti-inflammatory mediators that can contribute to or control tumor growth is essential for designing novel tumor therapies.

\section{Models to Analyze the Efficacy of New Therapies}

4.1. Assessment of Treatment Efficacy. In recent years, tumor therapies have achieved substantial but still incomplete success. It is generally accepted that well-characterized human tumor cell lines and in vivo animal models are required to develop novel antitumor treatments. Basically, four types of models have been developed (Table 3): (i) syngeneic murine models, (ii) syngeneic models with murine tumor cells engineered to express human antigens, (iii) human cells implanted into immunodeficient mice, and (iv) humanized mice, that is immunodeficient mice reconstituted with human immune system and then implanted with human tumor cells.

The standard treatment for aggressive B-cell malignancies is the combination of four chemotherapy agents (i.e., cyclophosphamide, doxorubicin, vincristine, and prednisolone) with rituximab, also called R-CHOP therapy [77]. Because B-lymphoma cells express the CD20 antigen, they are a suitable target for anti-CD20 monoclonal antibodies $(\mathrm{mAb})$ such as rituximab. The use of this chimeric mAb has enhanced the survival of patients with different B-cell malignancies, after various studies confirmed its therapeutic potential. Most of those studies used murine models of human tumor cell lines implanted into immunodeficient mice. For example, the efficacy of rituximab against disseminated Burkitt lymphoma Daudi cells and against DLBCL SU-DHL4 cells was assessed in SCID mice, and the therapeutic advantages varied with the cell line [59]. Hernandez-Ilizaliturri and colleagues [78] also used SCID mice, with the Raji cell line, and obtained better results: rituximab treatment enabled $60 \%$ of the animals to reject their tumors. This great potential has led many laboratories to seek to improve this efficacy by designing new engineered antibodies, such as EMAB-6 [79] or the humanized GA101 used against the human SUDHL4 tumor implanted into SCID/beige mice [80]. Coupling rituximab with other therapies has also been evaluated 

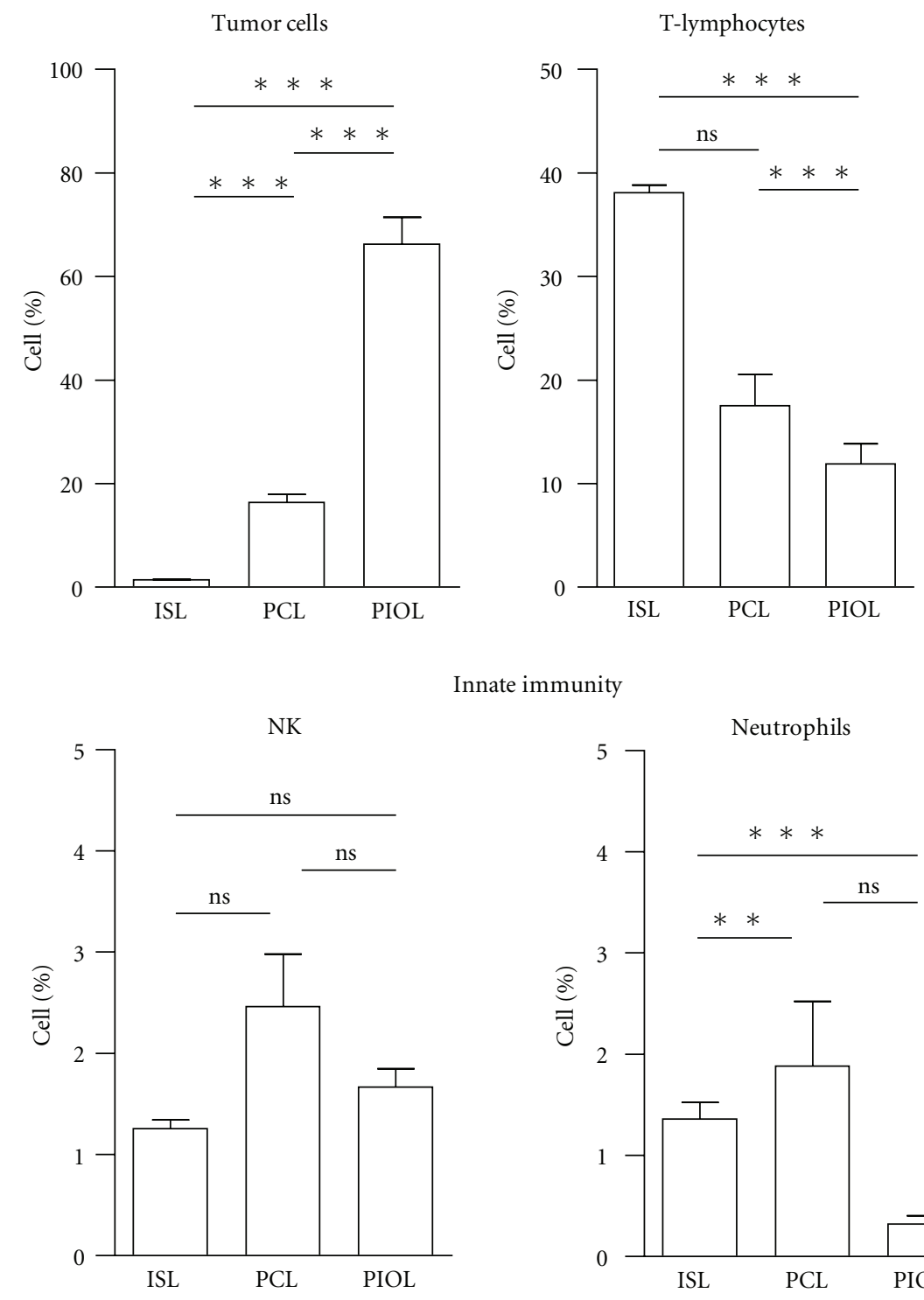

Innate immunity

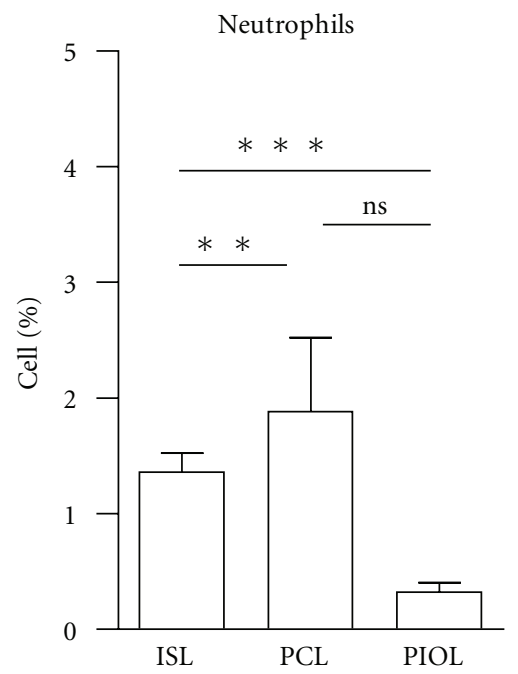

Antigen presenting cells
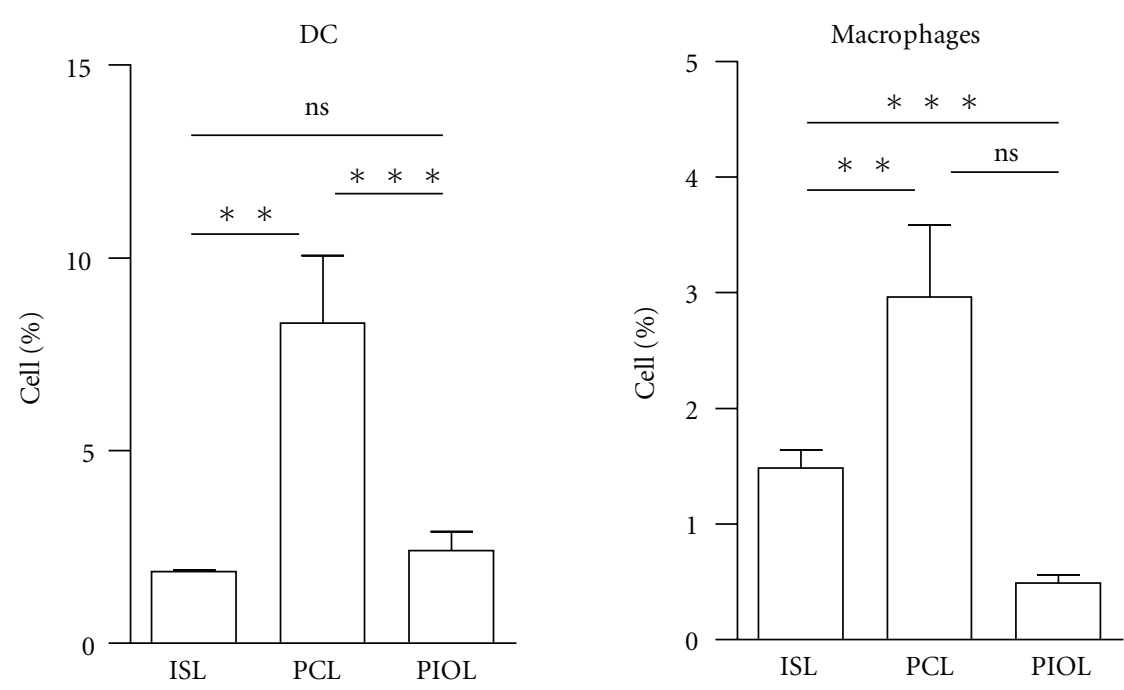

(a)

Figure 2: Continued. 


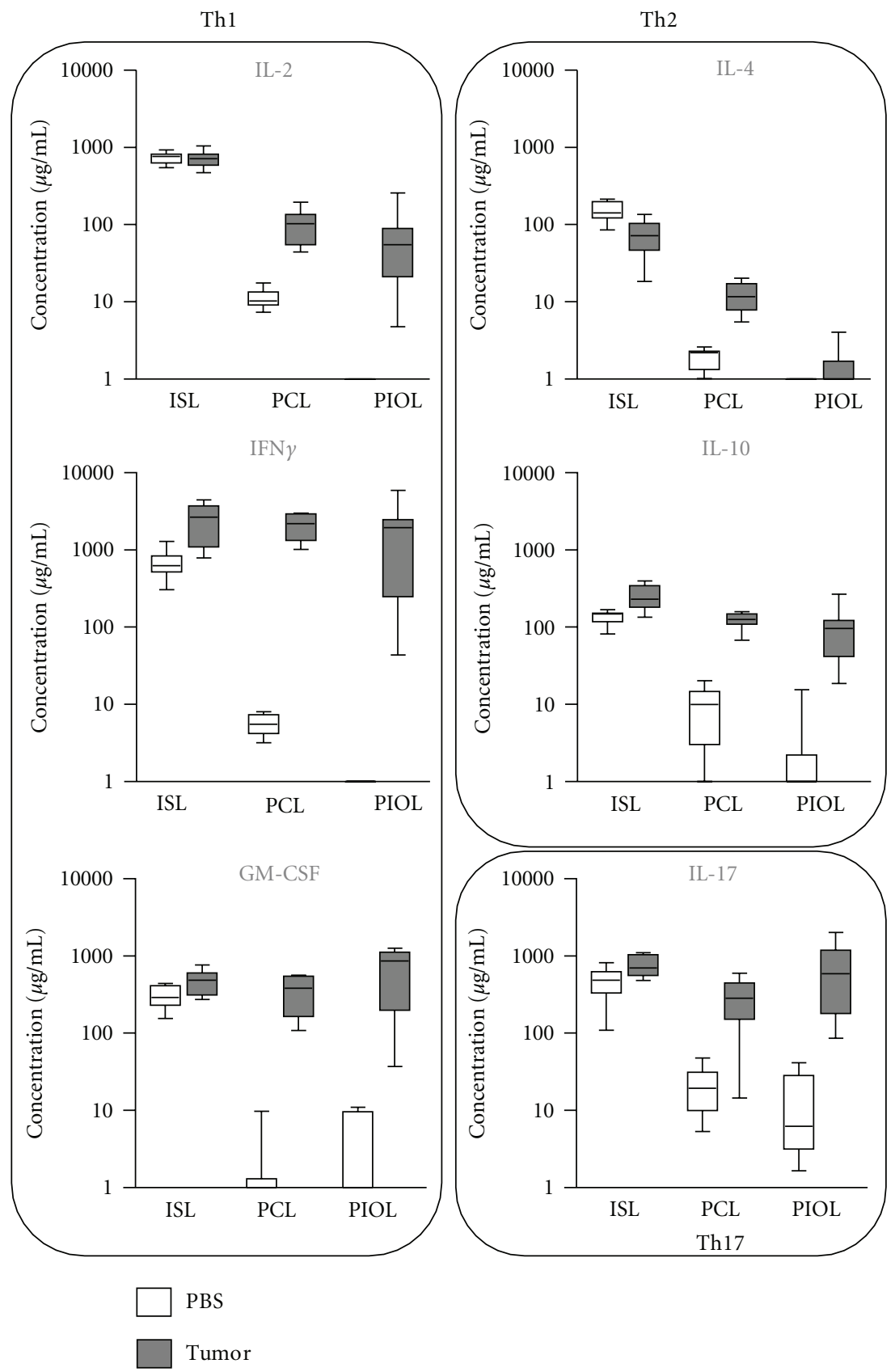

(b)

FIGURE 2: Comparison of the cellular and molecular immune environment of a B cell murine lymphoma implanted in the spleen, in the brain or in the eye. (a) A20.IIA-GFP cells were implanted in immunocompetent syngeneic mice in the spleen (intrasplenic lymphoma model: ISL), in the brain (primary intracerebral lymphoma model: PCL), or in the eye (primary intraocular lymphoma model: PIOL). 21 days after injection, tumor-bearing organs were analyzed by flow cytometry for the presence of $\mathrm{GFP}^{+}$tumor cells, $\mathrm{CD}^{+} \mathrm{T}$ lymphocytes, $\mathrm{NKp} 46^{+} \mathrm{NK}$ cells, $\mathrm{Gr} 1^{+}$neutrophils, $\mathrm{CD} 11 \mathrm{c}^{+}$dendritic cells, and $\mathrm{CD} 11 \mathrm{~b}^{+} \mathrm{CD} 11 \mathrm{c}^{-}$macrophages. Results are represented as the proportion of the different populations among total living cells $(n=10)$. (b) 21 days after lymphoma (gray boxes) or PBS (white boxes) injection, cells were isolated from appropriate tissues and stimulated for $36 \mathrm{~h}$ with anti-CD3/CD28-coated Dynal beads. Secretion of IL-2, IFN $\gamma$, GM-CSF, IL-4, IL-10, and IL-17 in the culture supernatant was evaluated by cytokine bead arrays (BD Biosciences) $(n=10)$. Animal studies were conformed to European Union guidelines and were approved by the Charles Darwin Ethics Committee in Animal Experiment, Paris, France. 
in these murine models of human tumors, as, for example, with R-CHOP therapy [81], or the TLR9 agonist CpG against Daudi cells [82]. Advances in understanding the biology of tumor cells and the tumor microenvironment have led to the design of new therapies, combined or not with preexisting ones (for review, see [83]). All of these strategies have been evaluated by implanting human cell lines into immunodeficient mice. They include the application of immunomodulatory drugs ([84]: subcutaneous Raji cells into SCID mice), inhibition of antiapoptotic signals ([65]: different cell lines into SCID or SCID/beige mice), or inhibition of specific metabolic or signaling pathways ([69]: intracerebral Raji cells into nude mice; [46]: subcutaneous HKBML cells into SCID mice). New strategies are also evaluated in this way, including the use of immunoconjugates ([73]: intraocular CA46 cells into SCID mice; [85]: intravenous Raji cells into SCID mice), or reoviruses, which target cells expressing high levels of the ras oncogene ([86]: subcutaneous Daudi and Raji cells into SCID/nod mice).

The major disadvantage of the experimental models described in this subsection is that they involve immunodeficient hosts that lack the adaptive immunity present in tumor microenvironment in humans, that do not reflect the complexity of human diseases.

4.2. Assessment of Immune System Involvement in Tumor Rejection. The role of the immune system is essential in tumor rejection. Syngeneic models, besides their utility in analysis of the tumor microenvironment, are particularly helpful for studying how specific treatments modulate the immune system or particular components of it. One of the indicators studied most frequently after treatment is the quantity of $\mathrm{T}$ lymphocytes, especially $\mathrm{CD}^{+} \mathrm{T}$ cells, infiltrating the tumor [87]. In an A20 B-cell lymphoma model implanted subcutaneously, treatment by survivin or an idiotype-binding peptide, is correlated with increased $\mathrm{CD}^{+} \mathrm{T}$-cell infiltration [63, 88]. Some therapies are clearly designed to boost immune response. For example, in the $4 \mathrm{TOO}$ intravenous model, administration of a vaccine composed of a fusion between dendritic cells and tumor cells increases T-lymphocyte proliferation and promotes the secretion of IL-2, IL-6, and IFN $\gamma$ (model listed in Table 3). In this model, significant amounts of IL-17 are found, which suggests that Th17-expressing cells contribute to tumor rejection [55]. Houot and Levy [87], in a two-site subcutaneous A20 model, tried to design an antitumor therapy based on the intratumoral inoculation of $\mathrm{CpG}$ and two T-cell-modulating mAbs. They obtained strong response rates and were able to demonstrate the involvement of $\mathrm{CD} 4^{+} \mathrm{T}$ cells in controlling the primary tumor site and the role of $\mathrm{CD}^{+} \mathrm{T}$ cells in controlling distant tumors.

Another significant advantage of murine models is the abundance of different mutant mice, deficient for wellcharacterized molecules or cell populations. For example, a subcutaneous Raji lymphoma model implanted into Fc $\gamma$ receptor-deficient mice demonstrated the importance of Fc receptors in the therapeutic efficacy of cytotoxic antibodies and the abolition of the anti-CD20 rituximab antitumor effect [89]. Additionally, Flynn and Stockinger [90] studied the role of specific $\mathrm{CD} 4^{+}$populations in the subcutaneous
LK35 tumor model with $\mathrm{Rag}^{-/-} \gamma \mathrm{c}^{-/-}$mice that lack all lymphocytes and NK cells. They demonstrated that memory $\mathrm{T}$ cells were capable of controlling tumor growth initially, without the help of other components of the immune system. However, immune pressure eventually led to selection of tumor cells unable to present antigens, which resulted in turn in paralysis of the $\mathrm{T}$-cell response.

Another potential way to obtain data more relevant to human tumors is to use murine cell lines expressing specific human tumor antigens, which would make it possible to test monoclonal antibodies against specific antigens. For example, the murine $38 \mathrm{C} 13$ cell line expressing the human CD20 antigen has been used to evaluate the therapeutic potential of rituximab against intravenously injected disseminated tumors [43] and against central nervous system tumors [68]. The authors showed in the first case [43] that depletion of neutrophils, NK cells, and macrophages did not influence antibody efficacy, but complement inhibition abolished this effect. More recently, others have used the EL4 thymoma cell line transfected with this same human CD20 antigen and the luciferase gene to monitor tumor regression after rituximab therapy [91, 92]. For now, the best system for studying tumor rejection appears to involve the reconstitution of immunodeficient mice with human immune cells to generate humanized mice, followed by the implantation of human tumor cells into these experimental animals. Sato and collaborators [93] developed this model to define the role of the complement system in the efficacy of an optimized variant of rituximab. In another example, human Daudi cells were implanted into SCID mice that were reconstituted with human peripheral blood leukocytes to assess the efficacy of a vaccine composed of immature dendritic cells and antihuman CD40 mAb [94]. This study demonstrated the rate at which activated $\mathrm{CD}^{+}$cytotoxic $\mathrm{T}$ lymphocytes infiltrate Burkitt lymphomas and the high level at which these cells secrete IFN $\gamma$ after the injection of this vaccine. More recently, a model was developed to test the efficacy of an agonistic anti-CD40 antibody against different subcutaneous B-cell tumor cell lines, such as Daudi, Raji, and Jijoye, implanted into SCID/beige mice. Although this type of treatment by itself reduced tumor size, it was much more effective after reconstitution of the mice with human $\mathrm{T}$ cells and dendritic cells [66].

In summary, antitumor immune responses hold great promise for boosting tumor therapy. More appropriate models are needed to explore the possibility of dendritic cell vaccination therapies in combination with specific tumor cell targeting.

\section{Conclusion}

Recent experimental animal models that allow us to study the induction and development of human tumors are important achievements. Only with a deeper understanding of the molecular and cellular mechanisms leading to tumor genesis and development of tumor microenvironments can we design better therapies. Despite the advances with the animal models described in this paper, several questions remain open. 
Given the difficulty in comparing murine tumors and human malignancies, more relevant models are needed. As this paper shows, there are many different models that seek to mimic human disease, but no consensus exists for any given model. Most tumor cells and spontaneous models require better characterization from histologic, phenotypic, genetic, and immunologic perspectives. Parallels with human diseases are also complicated by the absence of a clear classification of B-cell lymphomas. One interesting future challenge will be to develop a humanized murine model that can be implanted with human tumors and reconstituted with a complete human immune system for each main subclass of B-cell lymphomas. The remarkable impact that these models have had on the development of novel tumor therapies justifies the aggressive pursuit of basic and preclinical investigations to develop more appropriate animal models and unravel the fundamental processes governing the interaction of tumors with host tissues.

\section{Abbreviations}

B-NHL: B-cell non-Hodgkin lymphomas

CLL: Chronic lymphocytic leukemia

CNS: Central nervous system

DLBCL: Diffuse large B cell lymphoma

MALT: Mucosa associated lymphatic tissue

PCL: $\quad$ Primary cerebral lymphoma

PCNSL: Primary central nervous system lymphoma

PIOL: Primary intraocular lymphoma

SCID: Severe combined immune deficiency.

\section{Author's Contribution}

S. Donnou, C. Galand and V. Touitou performed experiments and analysed the data; S. Fisson conceived the study; S. Donnou wrote the paper; C. S. Fridman, Z. Fabry and S. Fisson contributed to the writing and to the critical reading of the paper.

\section{Conflict of Interests}

The authors declare that they have no financial conflict of interests.

\section{Acknowledgments}

This work was supported by the Institut National du Cancer (Grants RC013-C06N631-2005 and C06N748-2006), the Institut National de la Santé et de la Recherche Médicale, the University Pierre and Marie Curie, the University ParisDescartes, and the Association pour la Recherche contre le Cancer. S. Donnou was a recipient of a grant from the Institut National du Cancer. V. Touitou received study grants from the Fédération des Aveugles de France and the Fondation de France (Fouassier).

\section{References}

[1] E. R. Gerstner and T. T. Batchelor, "Primary central nervous system lymphoma," Archives of Neurology, vol. 67, no. 3, pp. 291-297, 2010.

[2] L. L. Lanier, M. Lynes, G. Haughton, and P. J. Wettstein, "Novel type of murine B-cell lymphoma," Nature, vol. 271, no. 5645, pp. 554-555, 1978.

[3] M. O. Shimada, Y. Yamada, Y. Nakakuki et al., "SL/KH strain F mice: a model of spontaneous pre-B-lymphomas," Leukemia Research, vol. 17, no. 7, pp. 573-578, 1993.

[4] R. D. Sheppard, S. A. Samant, M. Rosenberg, L. M. Silver, and M. D. Cole, "Transgenic N-myc mouse model for indolent B cell lymphoma: tumor characterization and analysis of genetic alterations in spontaneous and retrovirally accelerated tumors," Oncogene, vol. 17, no. 16, pp. 2073-2085, 1998.

[5] T. N. Fredrickson, K. Lennert, S. K. Chattopadhyay, H. C. Morse, and J. W. Hartley, "Splenic marginal zone lymphomas of mice," American Journal of Pathology, vol. 154, no. 3, pp. 805-812, 1999.

[6] J. Schmidt, K. Lumniczky, B. D. Tzschaschel et al., "Onset and dynamics of osteosclerosis in mice induced by Reilly-FinkelBiskis (RFB) murine leukemia virus: increase in bone mass precedes lymphomagenesis," American Journal of Pathology, vol. 155, no. 2, pp. 557-570, 1999.

[7] A. L. Kovalchuk, C. F. Qi, T. A. Torrey et al., "Burkitt lymphoma in the mouse," Journal of Experimental Medicine, vol. 192, no. 8, pp. 1183-1190, 2000.

[8] A. Egle, A. W. Harris, M. L. Bath, L. O’Reilly, and S. Cory, "VavP-Bcl2 transgenic mice develop follicular lymphoma preceded by germinal center hyperplasia," Blood, vol. 103, no. 6, pp. 2276-2283, 2004.

[9] K. M. Frank, N. E. Sharpless, Y. Gao et al., "DNA ligase IV deficiency in mice leads to defective neurogenesis and embryonic lethality via the p53 pathway," Molecular Cell, vol. 5, no. 6, pp. 993-1002, 2000.

[10] R. J. Greenwald, J. R. Tumang, A. Sinha et al., "E $\mu$-BRD2 transgenic mice develop B-cell lymphoma and leukemia," Blood, vol. 103, no. 4, pp. 1475-1484, 2004.

[11] G. Cattoretti, L. Pasqualucci, G. Ballon et al., "Deregulated BCL6 expression recapitulates the pathogenesis of human diffuse large B cell lymphomas in mice," Cancer Cell, vol. 7, no. 5, p. 445, 2005.

[12] R. J. Ford, L. Shen, Y. C. Lin-Lee et al., "Development of a murine model for blastoid variant mantle-cell lymphoma," Blood, vol. 109, no. 11, pp. 4899-4906, 2007.

[13] K. A. Field, S. Charoenthongtrakul, J. M. Michael, and Y. Refaeli, "Farnesyl transferase inhibitors induce extended remissions in transgenic mice with mature B cell lymphomas," Molecular Cancer, vol. 7, article 39, 2008.

[14] S. Mori, R. E. Rempel, J. T. Chang et al., "Utilization of pathway signatures to reveal distinct types of B lymphoma in the E $\mu$-myc model and human diffuse large B-cell lymphoma," Cancer Research, vol. 68, no. 20, pp. 8525-8534, 2008.

[15] Y. Kasama, S. Sekiguchi, M. Saito et al., "Persistent expression of the full genome of hepatitis $\mathrm{C}$ virus in B cells induces spontaneous development of B-cell lymphomas in vivo," Blood, vol. 116, no. 23, pp. 4926-4933, 2010.

[16] N. Puebla-Osorio, Y. Miyahara, S. Coimbatore et al., "Induction of B-cell lymphoma by UVB radiation in p53 haploinsufficient mice," BMC Cancer, vol. 11. article 36, 2011.

[17] D. Cozma, D. Yu, S. Hodawadekar et al., "B cell activator PAX5 promotes lymphomagenesis through stimulation of $\mathrm{B}$ 
cell receptor signaling," Journal of Clinical Investigation, vol. 117, no. 9, pp. 2602-2610, 2007.

[18] D. Yu and A. Thomas-Tikhonenko, "A non-transgenic mouse model for B-cell lymphoma: in vivo infection of p53-null bone marrow progenitors by a Myc retrovirus is sufficient for tumorigenesis," Oncogene, vol. 21, no. 12, pp. 1922-1927, 2002.

[19] L. W. Law and T. B. Dunn, "Observations on the effect of a folic-acid antagonist on transplantable," Journal of the National Cancer Institute, vol. 10, no. 1, pp. 179-192, 1949.

[20] J. V. Pulvertaft, "A study of malignant tumours in nigeria by short-term tissue culture," Journal of Clinical Pathology, vol. 18, pp. 261-273, 1965.

[21] G. Kohn, W. J. Mellman, P. S. Moorhead, J. Loftus, and G. Henle, "Involvement of C group chromosomes in five Burkitt lymphoma cell lines," Journal of the National Cancer Institute, vol. 38, no. 2, pp. 209-222, 1967.

[22] E. Klein, G. Klein, J. S. Nadkarni, J. J. Nadkarni, H. Wigzell, and P. Clifford, "Surface IgM-kappa specificity on a Burkitt lymphoma cell in vivo and in derived culture lines," Cancer Research, vol. 28, no. 7, pp. 1300-1310, 1968.

[23] G. Klein, B. Giovanella, A. Westman, J. S. Stehlin, and D. Mumford, "An EBV genome negative cell line established from an American Burkitt lymphoma; receptor characteristics. EBV infectibility and permanent conversion into EBV-positive sublines by in vitro infection," Intervirology, vol. 5, no. 6, pp. 319-334, 1975.

[24] G. B. Clements, G. Klein, and S. Povey, "Production by EBV infection of an EBNA positive subline from an EBNA negative human lymphoma cell line without detectable EBV DNA Vieillefond," International Journal of Cancer, vol. 16, no. 1, pp. 125-133, 1975.

[25] A. L. Epstein, M. M. Herman, and H. Kim, "Biology of the human malignant lymphomas. III. Intracranial heterotransplantation in the nude, athymic mouse," Cancer, vol. 37, no. 5, pp. 2158-2176, 1976.

[26] Y. Bergman and J. Haimovich, "Characterization of a carcinogen induced murine B lymphocyte cell line of $\mathrm{C} 3 \mathrm{H} / \mathrm{eB}$ origin," European Journal of Immunology, vol. 7, no. 7, pp. 413-417, 1977.

[27] S. Slavin and S. Strober, "Spontaneous murine B-cell leukaemia," Nature, vol. 272, no. 5654, pp. 624-626, 1978.

[28] K. J. Kim, C. Kanellopoulos Langevin, R. M. Merwin, D. H. Sachs, and R. Asofsky, "Establishment and characterization of BALB/c lymphoma lines with B cell properties," Journal of Immunology, vol. 122, no. 2, pp. 549-554, 1979.

[29] I. T. Magrath, C. B. Freeman, and P. Pizzo, "Characterization of lymphoma-derived cell lines: comparison of cell lines positive and negative for Epstein-Barr virus nuclear antigen. II. Surface markers," Journal of the National Cancer Institute, vol. 64 , no. 3, pp. 477-483, 1980.

[30] R. Ber and N. Lanir, "Fusion of plasmacytoma and host cells in vivo: selection of proliferating and nonproliferating cultures," Journal of the National Cancer Institute, vol. 72, no. 2, pp. 403409, 1984.

[31] W. M. Molenaar, H. Ellens, and H. M. Van den Berg, "Characterization of a high-grade malignant murine B-cell lymphoma and a study of its dissemination pattern after intraperitoneal or intravenous inoculation," Invasion and Metastasis, vol. 5, no. 4, pp. 206-217, 1985.

[32] M. Rowe, C. M. Rooney, A. B. Rickinson et al., "Distinctions between endemic and sporadic forms of Epstein-Barr viruspositive Burkitt's lymphoma," International Journal of Cancer, vol. 35 , no. 4, pp. 435-441, 1985.
[33] K. H. Th'ng, G. Garewal, and L. Kearney, "Establishment and characterization of three new malignant lymphoid cell lines," International Journal of Cancer, vol. 39, no. 1, pp. 89-93, 1987.

[34] P. B. Willoughby, J. C. Jennette, and G. Haughton, "Analysis of a murine B cell lymphoma, CH44, with an associated non-neoplastic T cell population. I. Proliferation of normal T lymphocytes is induced by a secreted product of the malignant B cells," American Journal of Pathology, vol. 133, no. 3, pp. 507515, 1988.

[35] H. C. Kluin-Nelemans, J. Limpens, J. Meerabux et al., "A new non-Hodgkin's B-cell line (DoHH2) with a chromosomal translocation $\mathrm{t}(14 ; 18)(\mathrm{q} 32 ; \mathrm{q} 21)$," Leukemia, vol. 5, no. 3, pp. 221-224, 1991.

[36] N. P. Sunil-Chandra, J. Arno, J. Fazakerley, and A. A. Nash, "Lymphoproliferative disease in mice infected with murine gammaherpesvirus 68," American Journal of Pathology, vol. 145, no. 4, pp. 818-826, 1994.

[37] M. D. Story, N. Mirkovic, N. Hunter, and R. E. Meyn, "Bcl-2 expression correlates with apoptosis induction but not tumor growth delay in transplantable murine lymphomas treated with different chemotherapy drugs," Cancer Chemotherapy and Pharmacology, vol. 44, no. 5, pp. 367-371, 1999.

[38] D. M. Jadayel, J. Lukas, E. Nacheva et al., "Potential rose for concurrent abnormalities of the cyclin D1, p16(CDKN2) and $\mathrm{p} 15(\mathrm{CDKN} 2 \mathrm{~B})$ genes in certain B cell non-Hodgkin's lymphomas. Functional studies in a cell line (Granta 519)," Leukemia, vol. 11, no. 1, pp. 64-72, 1997.

[39] T. Illidge, J. Honeychurch, A. Vandersteen, and M. Cragg, "Radioimmunotherapy in the $\pi$-BCL1 B cell lymphoma model: efficacy depends on more than targeted irradiation alone," Cancer Biotherapy and Radiopharmaceuticals, vol. 15, no. 6, pp. 581-591, 2000.

[40] M. L. Penichet, J. S. Dela Cruz, P. M. Challita-Eid, J. D. Rosenblatt, and S. L. Morrison, "A murine B cell lymphoma expressing human HER2/neu undergoes spontaneous tumor regression and elicits antitumor immunity," Cancer Immunology, Immunotherapy, vol. 49, no. 11, pp. 649-662, 2000.

[41] V. I. Kaledin, V. P. Nikolin, T. A. Ageeva et al., "Cyclophosphamide-induced apoptosis of murine lymphosarcoma cells in vivo," Voprosy Onkologii, vol. 46, no. 5, pp. 588-593, 2000.

[42] J. P. P. Meijerink, E. M. M. Van Lieshout, H. B. Beverloo et al., "Novel murine B-cell lymphoma/leukemia model to study BCL2-driven oncogenesis," International Journal of Cancer, vol. 114, no. 6, pp. 917-925, 2005.

[43] J. Golay, E. Cittera, N. Di Gaetano et al., "The role of complement in the therapeutic activity of rituximab in a murine B lymphoma model homing in lymph nodes," Haematologica, vol. 91, no. 2, pp. 176-183, 2006.

[44] L. J. Medeiros, Z. Estrov, and G. Z. Rassidakis, “Z-138 cell line was derived from a patient with blastoid variant mantle cell lymphoma," Leukemia Research, vol. 30, no. 4, pp. 497-501, 2006.

[45] V. Touitou, C. Daussy, B. Bodaghi et al., "Impaired Th1/Tc1 cytokine production of tumor-infiltrating lymphocytes in a model of primary intraocular B-cell lymphoma," Investigative Ophthalmology and Visual Science, vol. 48, no. 7, pp. 32233229, 2007.

[46] D. Muta, K. Makino, H. Nakamura, S. Yano, M. Kudo, and J. I. Kuratsu, "Inhibition of eIF4E phosphorylation reduces cell growth and proliferation in primary central nervous system lymphoma cells," Journal of Neuro-Oncology, vol. 101, pp. 3339, 2011. 
[47] U. Kapp, J. Wolf, C. Von Kalle et al., "Preliminary report: growth of Hodgkin's lymphoma derived cells in immune compromised mice," Annals of Oncology, vol. 3, supplement 4, pp. S21-S23, 1992.

[48] A. Enno, J. L. O’Rourke, C. R. Howlett, A. Jack, M. F. Dixon, and A. Lee, "MALToma-like lesions in the murine gastric mucosa after long-term infection with Helicobacter felis: a mouse model of Helicobacter pylori- induced gastric lymphoma," American Journal of Pathology, vol. 147, no. 1, pp. 217-222, 1995.

[49] D. Hanahan and R. A. Weinberg, "Hallmarks of cancer: the next generation," Cell, vol. 144, no. 5, pp. 646-674, 2011.

[50] S. Donnou, C. Galand, C. Daussy et al., "Immune adaptive microenvironment profiles in intracerebral and intrasplenic lymphomas share common characteristics," Clinical and Experimental Immunology, vol. 165, no. 3, pp. 329-337, 2011.

[51] R. J. Van Berlo, W. M. Molenaar, B. De Jong, W. Lemstra, J. Dokter, and A. W. T. Konings, "Cytogenetic characterization of a high-grade murine B-cell lymphoma," Cancer Genetics and Cytogenetics, vol. 38, no. 1, pp. 25-31, 1989.

[52] T. Illidge, J. Honeychurch, W. Howatt, F. Ross, B. Wilkins, and M. Cragg, "A new in vivo and in vitro B cell lymphoma model, $\pi$-BCL1," Cancer Biotherapy and Radiopharmaceuticals, vol. 15 , no. 6, pp. 571-580, 2000.

[53] J. M. Timmerman, C. B. Caspar, S. L. Lambert, A. D. Syrengelas, and R. Levy, "Idiotype-encoding recombinant adenoviruses provide protective immunity against murine B-cell lymphomas," Blood, vol. 97, no. 5, pp. 1370-1377, 2001.

[54] C. Chaise, E. Itti, Y. Petegnief et al., "[F-18]-fluoro-2-deoxyd-glucose positron emission tomography as a tool for early detection of immunotherapy response in a murine B cell lymphoma model," Cancer Immunology, Immunotherapy, vol. 56, no. 8, pp. 1163-1171, 2007.

[55] E. Alvarez, E. Moga, J. Barquinero, J. Sierra, and J. Briones, "Dendritic and tumor cell fusions transduced with adenovirus encoding CD40L eradicate B-cell lymphoma and induce a Th17-type response," Gene Therapy, vol. 17, no. 4, pp. 469$477,2010$.

[56] S. Dutt, J. Baker, H. E. Kohrt et al., "CD8 ${ }^{+} \mathrm{CD} 44^{h i}$ but not $\mathrm{CD} 4{ }^{+} \mathrm{CD} 44^{h i}$ memory $\mathrm{T}$ cells mediate potent graft antilymphoma activity without GVHD," Blood, vol. 117, no. 11, pp. 3230-3239, 2011.

[57] Y. Li, M. E. Williams, J. B. Cousar, A. W. Pawluczkowycz, M. A. Lindorfer, and R. P. Taylor, "Rituximab-CD20 complexes are shaved from Z138 mantle cell lymphoma cells in intravenous and subcutaneous SCID mouse models," Journal of Immunology, vol. 179, no. 6, pp. 4263-4271, 2007.

[58] D. Daniel, B. Yang, D. A. Lawrence et al., "Cooperation of the proapoptotic receptor agonist rhApo2L/TRAIL with the CD20 antibody rituximab against non-Hodgkin lymphoma xenografts," Blood, vol. 110, no. 12, pp. 4037-4046, 2007.

[59] J. S. Yan, X. Y. Chen, W. P. Li, Y. Yang, and Z. L. Song, "Establishing SCID mouse models of B-cell non-Hodgkin's lymphoma," Chinese Journal of Cancer, vol. 28, no. 2, pp. 181183, 2009.

[60] A. Curti, S. Pandolfi, B. Valzasina et al., "Modulation of tryptophan catabolism by human leukemic cells results in the conversion of CD25- into CD25 ${ }^{+}$T regulatory cells," Blood, vol. 109, no. 7, pp. 2871-2877, 2007.

[61] H. M. Dosch, D. M. G. Cochrane, V. A. Cook, J. S. Leeder, and R. K. Cheung, "Exogenous but not endogenous EBV induces lymphomas in beige/nude/xid mice carrying human lymphoid xenografts," International Immunology, vol. 3, no. 7, pp. 731735, 1991.
[62] K. A. Robertson, E. J. Usherwood, and A. A. Nash, "Regression of a murine gammaherpesvirus 68-positive B-cell lymphoma mediated by CD4 T lymphocytes," Journal of Virology, vol. 75, no. 7, pp. 3480-3482, 2001.

[63] C. Palmieri, C. Falcone, E. Iaccino et al., "In vivo targeting and growth inhibition of the A20 murine B-cell lymphoma by an idiotype-specific peptide binder," Blood, vol. 116, no. 2, pp. 226-238, 2010.

[64] P. C. Zamecnik and J. C. Long, "Growth of cultured cells from patients with Hodgkin's disease and transplantation into nude mice," Proceedings of the National Academy of Sciences of the United States of America, vol. 74, no. 2, pp. 754-758, 1977.

[65] S. Ackler, Y. Xiao, M. J. Mitten et al., "ABT-263 and rapamycin act cooperatively to kill lymphoma cells in vitro and in vivo," Molecular Cancer Therapeutics, vol. 7, no. 10, pp. 3265-3274, 2008.

[66] R. P. Gladue, T. Paradis, S. H. Cole et al., "The CD40 agonist antibody CP-870,893 enhances dendritic cell and Bcell activity and promotes anti-tumor efficacy in SCID-hu mice," Cancer Immunology, Immunotherapy, vol. 60, no. 7, pp. 1009-1017, 2011.

[67] C. L. Reinisch, A. P. Sing, and E. R. Bacon, "Regulation of B cell lymphomagenesis by a malignant Qa1+ inducer T cell clone," Journal of Experimental Medicine, vol. 159, no. 3, pp. 906-920, 1984.

[68] J. F. Mineo, A. Scheffer, C. Karkoutly et al., "Using human CD20-transfected murine lymphomatous B cells to evaluate the efficacy of intravitreal and intracerebral rituximab injections in mice," Investigative Ophthalmology and Visual Science, vol. 49, no. 11, pp. 4738-4745, 2008.

[69] W. Wang, A. Kardosh, Y. S. Su, A. H. Schonthal, and T. C. Chen, "Efficacy of celecoxib in the treatment of CNS lymphomas: an in vivo model," Neurosurgical focus, vol. 21, no. 5, p. E14, 2006.

[70] L. Jiang, L. A. Marlow, S. J. Cooper et al., "Selective central nervous system tropism of primary central nervous system lymphoma," International Journal of Clinical and Experimental Pathology, vol. 3, no. 8, pp. 763-767, 2010.

[71] L. L. Muldoon, S. J. Lewin, E. Dósa et al., "Imaging and therapy with rituximab anti-CD20 immunotherapy in an animal model of central nervous system lymphoma," Clinical Cancer Research, vol. 17, no. 8, pp. 2207-2215, 2011.

[72] D. Brandsma, L. Ulfman, J. C. Reijneveld et al., "Constitutive integrin activation on tumor cells contributes to progression of leptomeningeal metastases," Neuro-Oncology, vol. 8, no. 2, pp. 127-136, 2006.

[73] Z. Li, S. P. Mahesh, D. F. Shen et al., "Eradication of tumor colonization and invasion by a B cell-specific immunotoxin in a murine model for human primary intraocular lymphoma," Cancer Research, vol. 66, no. 21, pp. 10586-10593, 2006.

[74] K. G. Elpek, C. Lacelle, N. P. Singh, E. S. Yolcu, and H. Shirwan, "CD4 ${ }^{+} \mathrm{CD} 25^{+} \mathrm{T}$ regulatory cells dominate multiple immune evasion mechanisms in early but not late phases of tumor development in a B Cell Lymphoma Model," Journal of Immunology, vol. 178, no. 11, pp. 6840-6848, 2007.

[75] P. Serafini, S. Mgebroff, K. Noonan, and I. Borrello, "Myeloidderived suppressor cells promote cross-tolerance in B-cell lymphoma by expanding regulatory T cells," Cancer Research, vol. 68, no. 13, pp. 5439-5449, 2008.

[76] C. Kadoch, E. B. Dinca, R. Voicu et al., "Pathologic correlates of primary central nervous system lymphoma defined in an orthotopic xenograft model," Clinical Cancer Research, vol. 15, no. 6, pp. 1989-1997, 2009. 
[77] N. Niitsu, "Current treatment strategy of diffuse large B-cell lymphomas," International Journal of Hematology, vol. 92, no. 2, pp. 231-237, 2010.

[78] F. J. Hernandez-Ilizaliturri, V. Jupudy, J. Ostberg et al., "Neutrophils contribute to the biological antitumor activity of rituximab in a non-hodgkin's lymphoma severe combined immunodeficiency mouse model," Clinical Cancer Research, vol. 9, no. 16, pp. 5866-5873, 2003.

[79] C. De Romeuf, C. A. Dutertre, M. Le Garff-Tavernier et al., "Chronic lymphocytic leukaemia cells are efficiently killed by an anti-CD20 monoclonal antibody selected for improved engagement of Fc $\gamma$ RIIIA/CD16," British Journal of Haematology, vol. 140, no. 6, pp. 635-643, 2008.

[80] E. Mössner, P. Brünker, S. Moser et al., "Increasing the efficacy of CD20 antibody therapy through the engineering of a new type II anti-CD20 antibody with enhanced direct and immune effector cell-mediated B-cell cytotoxicity," Blood, vol. 115, no. 22, pp. 4393-4402, 2010.

[81] S. Ackler, M. J. Mitten, K. Foster et al., "The Bcl-2 inhibitor ABT-263 enhances the response of multiple chemotherapeutic regimens in hematologic tumors in vivo," Cancer Chemotherapy and Pharmacology, vol. 66, no. 5, pp. 869-880, 2010.

[82] V. Buhé, J. O. Pers, R. Marianowski, C. Berthou, P. Youinou, and S. Loisel, "Development of a Murine model to dissect the CpG-oligonucleotide-enhancement of the killing of human B Cells by rituximab," Journal of Autoimmunity, vol. 34, no. 2, pp. 136-144, 2010.

[83] C. B. Reeder and S. M. Ansell, "Novel therapeutic agents for Bcell lymphoma: developing rational combinations," Blood, vol. 117, no. 5, pp. 1453-1462, 2011.

[84] N. Reddy, F. J. Hernandez-Ilizaliturri, G. Deeb et al., "Immunomodulatory drugs stimulate natural killer-cell function, alter cytokine production by dendritic cells, and inhibit angiogenesis enhancing the anti-tumour activity of rituximab in vivo," British Journal of Haematology, vol. 140, no. 1, pp. 36-45, 2008.

[85] G. L. Griffiths, M. J. Mattes, R. Stein et al., "Cure of SCID mice bearing human B-lymphoma xenografts by an anti-CD74 antibody-anthracycline drug conjugate," Clinical Cancer Research, vol. 9, no. 17, pp. 6567-6571, 2003.

[86] T. Alain, K. Hirasawa, K. J. Pon et al., "Reovirus therapy of lymphoid malignancies," Blood, vol. 100, no. 12, pp. 41464153, 2002.

[87] R. Houot and R. Levy, "T-cell modulation combined with intratumoral CpG cures lymphoma in a mouse model without the need for chemotherapy," Blood, vol. 113, no. 15, pp. 35463552, 2009.

[88] U. Harnack, K. Eckert, I. Fichtner, and G. Pecher, "Oral administration of a soluble 1-3, 1-6 $\beta$-glucan during prophylactic survivin peptide vaccination diminishes growth of a $\mathrm{B}$ cell lymphoma in mice," International Immunopharmacology, vol. 9, no. 11, pp. 1298-1303, 2009.

[89] R. A. Clynes, T. L. Towers, L. G. Presta, and J. V. Ravetch, "Inhibitory Fc receptors modulate in vivo cytoxicity against tumor targets," Nature Medicine, vol. 6, no. 4, pp. 443-446, 2000.

[90] S. Flynn and B. Stockinger, "Tumor and CD4 T-cell interactions: tumor escape as result of reciprocal inactivation," Blood, vol. 101, no. 11, pp. 4472-4478, 2003.

[91] D. Daydé, D. Ternant, M. Ohresser et al., "Tumor burden influences exposure and response to rituximab: pharmacokinetic-pharmacodynamic modeling using a syngeneic bioluminescent murine model expressing human CD20," Blood, vol. 113, no. 16, pp. 3765-3772, 2009.
[92] R. Abès, E. Gélizé, W. H. Fridman, and J. L. Teillaud, "Longlasting antitumor protection by anti-CD20 antibody through cellular immune response," Blood, vol. 116, no. 6, pp. 926-934, 2010.

[93] F. Sato, A. Ito, T. Ishida et al., "A complement-dependent cytotoxicity-enhancing anti-CD20 antibody mediating potent antitumor activity in the humanized NOD/Shi-scid, IL2R $y^{\text {null }}$ mouse lymphoma model," Cancer Immunology, Immunotherapy, vol. 59, no. 12, pp. 1791-1800, 2010.

[94] Y. Ge, H. Xi, and X. G. Zhang, "Vaccination with immature dendritic cells combined with $\mathrm{CD} 40 \mathrm{mAb}$ induces protective immunity against B lymphoma in hu-SCID mice," Biomedicine and Pharmacotherapy, vol. 64, no. 7, pp. 487-492, 2010. 


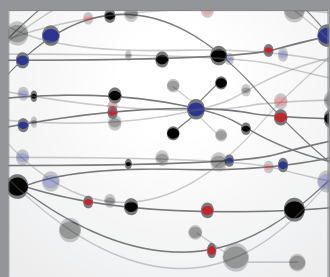

The Scientific World Journal
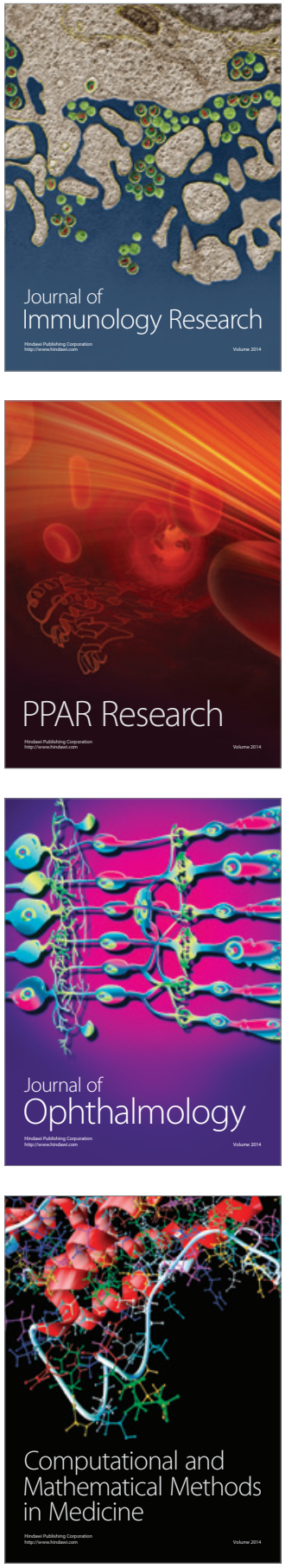

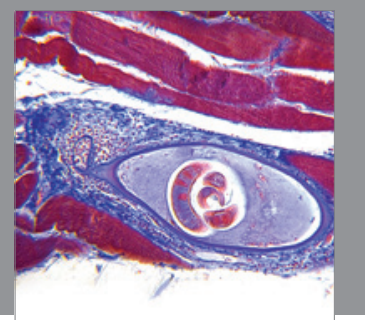

Gastroenterology

Research and Practice
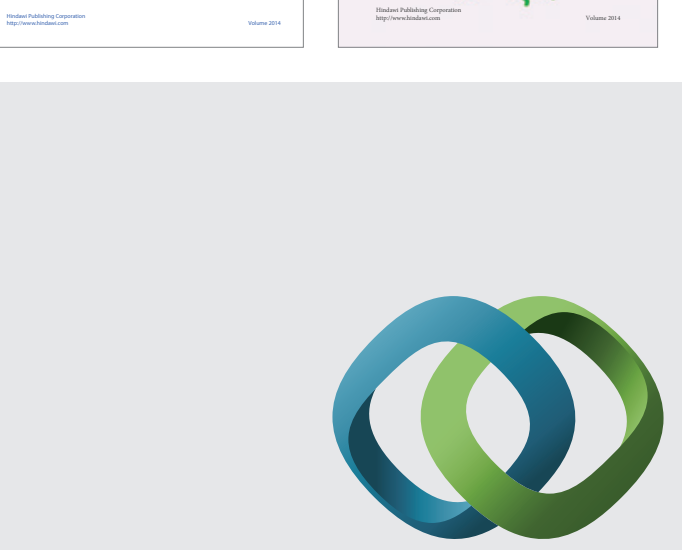

\section{Hindawi}

Submit your manuscripts at

http://www.hindawi.com
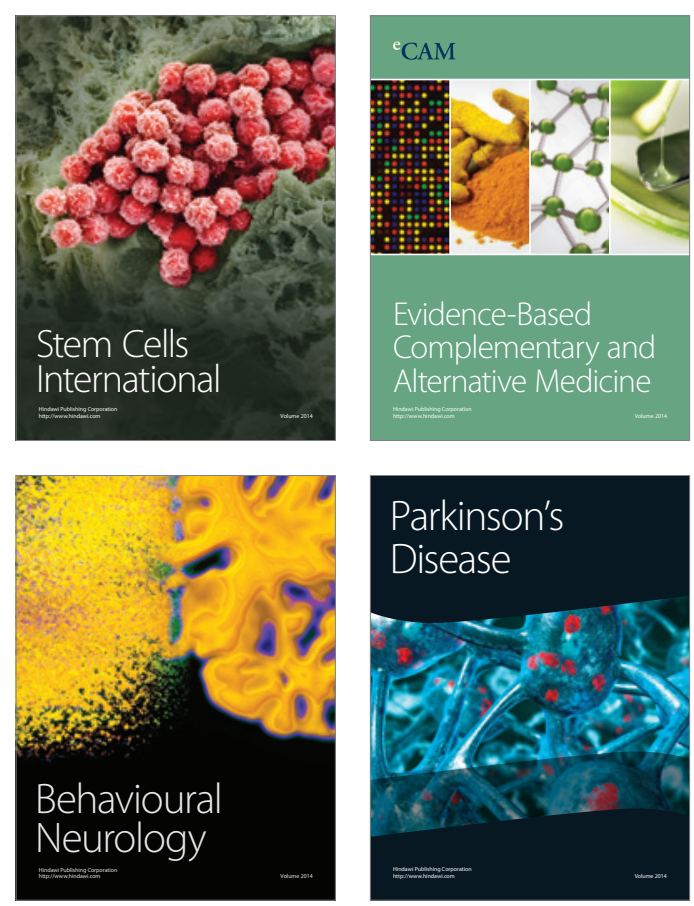

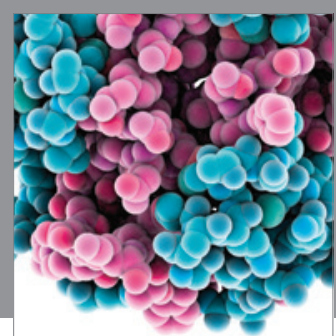

Journal of
Diabetes Research

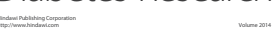

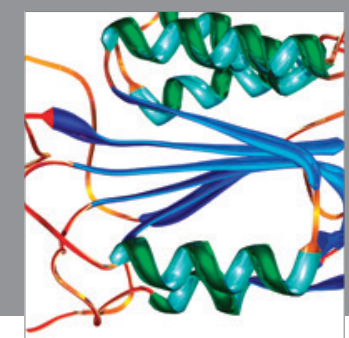

Disease Markers
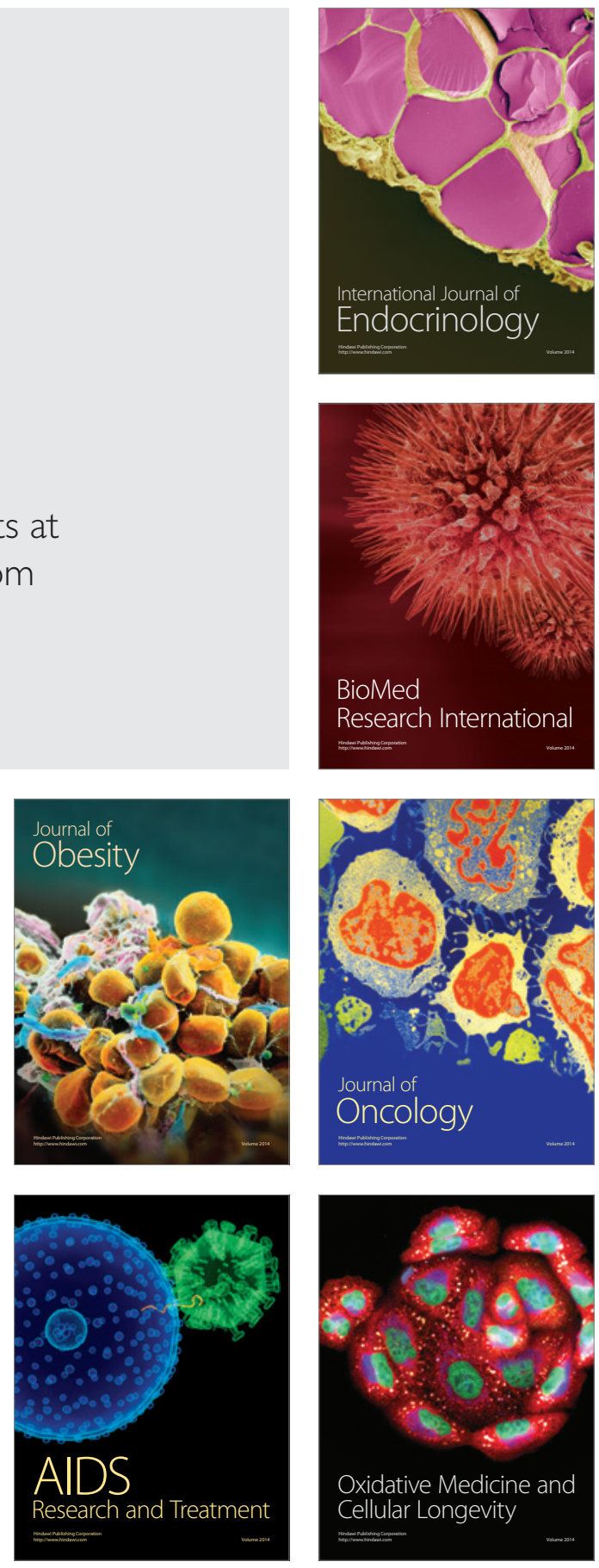